\title{
EVOLUÇÃO INTERPRETATIVA DA SUPREMA CORTE DOS ESTADOS UNIDOS DA AMÉRICA ENTRE OS ANOS DE 1803 e 1954
}

\author{
Paulo Roberto Barbosa Ramos ${ }^{1}$ \\ Sahid Sekeff Simão Alencar ${ }^{2}$
}

Resumo: O objetivo principal deste artigo é compreender a evolução interpretativa implementada pela Suprema Corte dos Estados Unidos da América em seus precedentes datados entre 1803 e 1954, evidenciando-se a não homogeneidade desse processo. Dentro desse lapso temporal, diversos precedentes de garantias de liberdades civis serão analisados com o fim de elucidar a hermenêutica adotada pela Corte a partir de 1937, com especial ênfase nos pertinentes a temática de discriminação racial e seus reflexos na sociedade norteamericana. Para tanto, a metodologia aplicada foi a revisão bibliográfica e documental.

Palavras-chave: Suprema Corte; Estados Unidos da América; Evolução interpretativa; Moderação Judiciária; Discriminação racial.

\section{INTERPRETATIVE EVOLUTION OF THE SUPREME COURT OF THE UNITED STATES OF AMERICA BETWEEN THE YEARS OF 1803 AND 1954}

\begin{abstract}
The main objective of this article is to understand the interpretative evolution implemented by the Supreme Court of the United States of America in its precedents between 1803 and 1954, evidencing the non-homogeneity of this process. Within this temporal period, several precedents of guarantees of civil liberties will be analyzed in order to elucidate the hermeneutics adopted by the Court from 1937, with special emphasis on the themes of racial discrimination and its repercussions in American society. For that, the applied methodology was the bibliographical and documentary.
\end{abstract}

Keywords: Supreme Court; United States of America; Interpretative evolution; Judicial Moderation; Racial discrimination.

\section{Introdução}

A evolução interpretativa da Suprema Corte dos Estados Unidos da América (EUA) somente é possível de ser compreendida ao regredir-se aos pilares formadores da própria Common Law. Em decorrência de um processo histórico ímpar, a Common Law foi

\footnotetext{
${ }^{1}$ Doutorado em Direito Constitucional pela Pontifícia Universidade Católica de São Paulo (2001) e PósDoutorado em Direito Constitucional pela Universidade de Granada - Espanha (2010/2011). Atualmente é Professor Associado IV da Universidade Federal do Maranhão, Coordenador do Núcleo de Estudos de Direito Constitucional dessa mesma instituição, Professor Pesquisador do Centro Universitário do Maranhão e Promotor de Justiça de Controle Externo da Atividade Policial do Ministério Público do Estado do Maranhão. Ministra a disciplina Direito Constitucional Avançado nos Programas de Mestrado e Doutorado da Universidade Autônoma de Lisboa.

${ }^{2}$ Mestrando em Direito e Instituições do Sistema de Justiça (Universidade Federal do Maranhão), na linha de pesquisa "As instituições internacionais do sistema de justiça".
}

Revista Brasileira de Teoria Constitucional | e-ISSN: 2526-0251 | Porto Alegre | v. 4 | n. 2 | p. 44 - 65 | Jul/Dez. 2018 
desenvolvida paulatinamente pelos juízes, a partir de casos concretos, diferindo-se da Civil Law (marcada por ter dado continuidade aos pressupostos jurídicos romano-germânicos).

A Common Law comporta-se como um "sistema aberto", visto possibilitar ao julgador solucionar qualquer litígio ou questão colocada diante dele, distanciando-se de generalidades. Como decorrência, tornou-se essencialmente jurisprudencial. As regras jurídicas advirão, na essência, do estatuído na ratio decidendi das decisões das cortes superiores, apegando-se a solucionar de maneira imediata os conflitos.

Postura completamente distinta dos ordenamentos jurídicos que emanaram da tradição romano-germânica, marcados por "sistemas fechados", nos quais os conflitos serão ou poderão ser resolvidos, desde que tenha havido a formulação de uma regra jurídica préexistente àqueles. Imprescindíveis, sob essa lógica, os papéis executados pelas doutrinas e universidades na sistematização do direito. Juristas doutrinados nessa tradição poderiam concluir, precipitadamente, que o sistema de precedentes enrijece o direito, conferindo até mesmo um caráter de automatismo, como se não houvesse uma racionalização. Tal raciocínio é falacioso, pois há uma devida dinamicidade naquele ordenamento, prezando-se por mecanismos de garantia à segurança jurídica.

A Corte Suprema dos EUA, em seus julgados, mantém uma hermenêutica que acompanha a evolução da sociedade, sempre com o intuito de desencadear estabilidade às suas instituições jurídicas. Conforme será visto a seguir, entre os anos de 1890 a 1937, a Corte imiscuiu-se ativamente no âmbito legislativo, adquirindo pejorativamente o título de “superlegislativo". Todavia, em 1937, ela muda profundamente sua postura ante a apreciação dos casos apresentados, pautando-se por maior moderação sem perder sua efetividade, principalmente, na garantia de direitos fundamentais, além de manter o equilíbrio entre as jurisdições estaduais e a federal.

A jurisprudência da Corte clarifica sua evolução interpretativa, especialmente a envolvida com a temática de discriminação racial. Ocorre que diversos Estados, especialmente sulistas, após a Guerra Civil, potencializaram um sentimento de inferioridade dos negros, mesmo após a abolição da escravidão, almejando implementar meios de se manter uma segregação a esses. Diante dessa constatação, paulatinamente, a Suprema Corte busca dissolver esse preconceito histórico ao possibilitar uma efetiva transição de uma igualdade e liberdade formais para outras mais substanciais. 


\section{Evolução interpretativa da Suprema Corte dos Estados Unidos da América}

Nos EUA, a Constituição Federal desempenhou um papel muito além da organização das instituições políticas do país, característica advinda da preocupação das 13 (treze) colônias iniciais em preservar suas liberdades civis, em detrimento da perseguição religiosa vivenciada na metrópole inglesa.

Os colonos da América não interpretaram como positiva a oralidade presente no direito inglês, a qual tornava a sociedade vulnerável a arbítrios dos governantes, além de fragilizar a garantia dos seus direitos. Incentivou-se, então, a adoção da lei escrita, com reflexo direto sobre a futura elaboração da constituição nacional.

A constituição estadunidense não se assemelhou à common law inglesa, em que as leis detinham a mera função de complemento ou ratificação às jurisprudências. A própria fundação dos EUA é inferida da constituição, tanto que refletirá uma nova perspectiva de contrato social, fixando uma Bill of Rights (Declaração dos Direitos), na qual se estabeleceu de maneira nítida os limites da intervenção estatal na esfera privada.

Atualmente, a Bill of Rights, de maneira uníssona, é amplamente valorizada pelos estadunidenses, associada ao fortalecimento das liberdades individuais. Conquanto, logo após a Guerra da Independência, houve um intenso debate promovido pelos federalistas e os antifederalistas, incluindo a real necessidade de se explicitar um conjunto de direitos fundamentais na Constituição.

A Suprema Corte viu-se impelida, diante da rigidez e caráter sintético, em manter uma hermenêutica versátil na interpretação da Constituição. Esse processo é mais acanhado nos Supremos Tribunais dos Estados por deterem um posicionamento mais conservador. Mudanças na jurisprudência, em grande parte, somente ocorrem pela pressão da opinião dos juristas, além da aspiração em alinhar o direito de um Estado com a corrente dominante que prevaleceu noutros, restabelecendo, dentro do possível, uma unidade da common law.

A partir de 1803, com o surgimento da doutrina do Judicial Review (controle judicial da constitucionalidade das leis), a Suprema Corte intensificou um papel criativo ante a interpretação das leis. Contudo, após 1937, a mesma Corte mudou substancialmente sua hermenêutica, o que foi titulado por Edward Samuel Corwin, ex-presidente da American Political Science Association, como "Revolução Constitucional de 1937.” (CORWIN, s/d, p. 176).

Revista Brasileira de Teoria Constitucional | e-ISSN: 2526-0251 | Porto Alegre | v. 4 | n. 2 | p. 44 - 65 | Jul/Dez. 2018 


\title{
1.1. Doutrina da "Supremacia Judiciária"
}

Como fruto do comportamento proativo da Suprema Corte, o controle judicial da constitucionalidade das leis não resultou de uma legislação expressa, mas do Caso Marbury v. Madison, datado de 1803. Esse se perpetuou ao longo dos séculos, sem sofrer oposição, permitindo que a Corte julgasse a constitucionalidade das normas dos Estados, tanto no aspecto material como formal, anulando-as quando ferissem os princípios estatuídos na Constituição. Digno de nota, nesse sentido, o artigo de $n^{\circ} .78$ dos Federalistas:

\begin{abstract}
A Constituição é e deve ser considerada pelos juízes como lei fundamental; e como a interpretação das leis é a função especial dos tribunais judiciários, a eles pertence determinar o sentido da Constituição, assim como de todos os outros atos do corpo legislativo. Se entre estas leis se encontrarem algumas contraditórias, deve preferir aquela, cuja observância é um dever mais sagrado; que é o mesmo que dizer que a Constituição deve ser preterida a um simples estatuto; ou a intenção do povo à dos seus agentes. (HAMILTON et al, 2002, p. 460).
\end{abstract}

Apesar da relevância histórica atribuída ao precedente Marbury v. Madison, o controle judicial, exercido pela Suprema Corte, teria a árdua missão de harmonizar-se com o legislativo nacional, incluindo, em grau menor, os legislativos estaduais.

Entre os anos de 1890 a 1937, a Corte pautou-se pelo laissez-faire, interferindo na função governamental. O Caso United States v. Butler, datado de 1936, representa a melhor síntese desse período:

[...] este Tribunal arroga-se o poder de dominar ou controlar a ação dos representantes do povo. Isso é uma interpretação errônea. A Constituição é a suprema lei do país, ordenada e estabelecida pelo povo. Toda a legislação deve conformar-se aos princípios fixados por ela. Quando uma lei do Congresso é adequadamente contestada nos tribunais, por não se conformar ao mandamento constitucional, o ramo judiciário do governo só tem um dever a cumprir: pôr o artigo da Constituição que é invocado ao lado da lei que é contestada e decidir se esta última está de acordo com aquele artigo. (United States v. Butler, 297 U.S I, 62 apud SCHWARTZ, 1955, p. 259).

O amadurecimento da presente doutrina, denominada de "Supremacia Judiciária", materializou-se no Caso Lochner v. New York, de 1905. Nesse litígio, o autor questionava a constitucionalidade de uma lei nova-iorquina, na qual se fixou a jornada de trabalho máxima dos padeiros. Ora, ao se fazer uma interpretação literal da constituição, infere-se a inexistência de qualquer norma que delegue competência ao Executivo para regulamentação 
dessa temática trabalhista. Essa limitação foi contornada pela Corte ao deduzir que a "compra e venda" da força de trabalho advinha das Emendas V e XIV:

\section{EMENDA V}

Ninguém será detido para responder por crime capital [...]; nem ser privado da vida, liberdade, ou bens, sem processo legal; [...] (TRADUÇÃO NOSSA) (GRIFO NOSSO).

\section{EMENDA XIV}

Seção 1 [...] nenhum Estado poderá fazer ou executar leis restringindo os privilégios ou as imunidades dos cidadãos dos Estados Unidos; nem poderá privar qualquer pessoa de sua vida, liberdade, ou bens sem processo legal, ou negar a qualquer pessoa sob sua jurisdição a igual proteção das leis (TRADUÇÃO NOSSA) (GRIFO NOSSO). ${ }^{3}$

A partir da expressão "vida, liberdade, ou bens, sem processo legal”, a Corte concluiu pela liberdade contratual, consequentemente, invalidando a legislação em questão. Mascarava-se um questionamento valorativo da lei, segundo parâmetros da Corte, que os considerava como reflexo de um julgamento objetivo e independente. Na época, essa decisão desencadeou uma ampla repercussão, incluindo vultuosas críticas que consideravam a Corte como um "superlegislativo".

\subsection{Doutrina da "Moderação Judiciária"}

Diante de uma ampla rejeição popular, juntamente com a discordância no campo jurídico, houve a rejeição da ratio decidendi proferida no caso Lochner v. New York. Paulatinamente, a primazia da Corte, marca característica da "Supremacia Judiciária", adotada de 1890 a 1936, foi substituída por uma posição mais branda.

Nessa nova fase interpretativa, posicionamento preservado até os presentes dias, articulou-se a doutrina da "Moderação Judiciária". Essa já havia sido prenunciada anteriormente no voto dissidente do juiz Oliver Wendell Holmes Júnior, ainda no precedente Lochner, ao advogar que uma lei não deveria ser tida como inconstitucional "[...] a não ser que se possa dizer que um indivíduo justo e racional forçosamente admitiria que a lei proposta infringiria os princípios fundamentais entendidos pelas tradições de nosso povo e nossas leis." (Lochner v. New York, 198 U.S. em 76 apud SCHWARTZ, 1955, p. 261).

\footnotetext{
${ }^{3}$ No original: "No person shall be held to answer for a capital [...] nor be deprived of life, liberty, or property, without due process of law [...]"; e "No State shall make or enforce any law which shall abridge the privileges or immunities of citizens of the United States; nor shall any State deprive any person of life, liberty, or property, without due process of law; nor deny to any person within its jurisdiction the equal protection of the laws". (UNITED STATES SENATE, 2018).
} 
Os juízes perscrutarão a existência de uma base racional para a medida legislativa, caso haja, independentemente de juízos axiológicos, será preservada. Há uma subjetividade na análise, contudo adota-se como guia se um legislador consideraria essa lei como "sensata" a fim de alcançar seus resultados desejados.

Após 1937, quando da assimilação da presente doutrina, somente em um caso a Suprema Corte declarou a inconstitucionalidade de uma lei do Congresso, trata-se do Caso United States v. Lovett. Ao se analisar minudentemente, não se trata de uma exceção, ainda em consonância com os parâmetros citados acima.

Lovett, Dodd e Watson eram três funcionários públicos federais, cujos serviços advinham de longa data e eram respeitados em suas repartições. Ocorre que, em decorrência de serem acusados por "atitudes subversivas" por uma comissão da House of Representatives (Câmara dos Representantes), foram tidos como “incapazes" de servir o poder público e, portanto, deveriam ser exonerados. Os órgãos públicos, em que trabalhavam aqueles funcionários, discordaram dessa decisão e não a cumpriram. Como resposta, a Câmara aprovou um aditamento à lei de concessão de verbas de 1943, proibindo o repasse financeiro para pagamento dos salários daqueles. O Senado, após 6 (seis) recusas ao aditamento, desistiu de se contrapor ao mesmo, concordando. Ao presidente Roosevelt, ainda residia a possibilidade de vetar, contudo não o fez pela pressão do encerramento do ano fiscal, e porque não o podia fazer exclusivamente quanto ao aditamento, sem que vetasse o projeto inteiro.

O caso, após os devidos trâmites legais, chegou a apreciação pela Suprema Corte, enquadrando-o como inconstitucional em decisão proferida em 1946. O aditamento ao projeto de lei foi tido como um "decreto de proscrição", algo que a Constituição não possibilitava na promulgação de leis, conforme o art. $1^{\circ}$, seção $09^{4}$. A compreensão desse instituto originou-se do Caso Cummings v. Missouri, de 1866, ao interpretá-lo como um ato legislativo que infligiu punição a um cidadão sem um devido julgamento judicial. A situação agravava-se, pois além de ausente um julgamento judicial, não havia lei anterior que o definisse.

Sobre esse posicionamento mais brando da Suprema Corte, o professor Bernard Schwart concluiu:

[...] a atitude da Corte Suprema, hoje, com respeito ao seu poder de declarar inconstitucional alguma lei, certamente representa uma transformação drástica e

\footnotetext{
${ }^{4}$ No original: "No Bill of Attainder or ex post facto Law shall be passed.” (UNITED STATES SENATE, 2018).

Revista Brasileira de Teoria Constitucional | e-ISSN: 2526-0251 | Porto Alegre | v. 4 | n. 2 | p. 44 - 65 | Jul/Dez. 2018
} 
comparação com as Cortes anteriores. A Corte Suprema não pode ser mais acusada de exercer as funções de um superlegislativo, que decide sobre a propriedade da legislação de acordo com a sua própria ideia de razoabilidade. (SCHWARTZ, 1955, p. 264).

O presente amadurecimento foi fruto de uma percepção da Corte de não contender com o Congresso, tornando-se um atributo permanente. Incoerentes, portanto, os que advogam que essa mudança foi fruto de crenças políticas dos presidentes que nomearam "seus juízes" para a Suprema Corte. Constatou-se que uma declaração de inconstitucionalidade irradia sérias consequências no plano jurídico e político, devendo ter um caráter de subsidiariedade caso houvesse outro meio. Ora, o Congresso, cujo poder advém da legitimidade democrática, detém maior maleabilidade para correção dos seus erros, e, caso não o faça, o povo alterará naturalmente sua composição.

\subsubsection{Teoria das "Questões políticas"}

Como consectário lógico da doutrina da "Moderação Judiciária", a Suprema Corte estabeleceu que em um conjunto de temáticas, tipificadas como "Questões Políticas”, em decorrência de sua própria natureza, as decisões finais caberiam não aos tribunais, mas aos órgãos políticos do Governo. A origem dessa limitação advém da teoria inglesa dos "atos de Estado", focados principalmente na discricionariedade do governo no trato das relações exteriores.

A Corte americana potencializou a teoria inglesa, superando seu elemento restritivo, tornando-a englobante de matérias cujo enquadramento como "Questões Políticas" derivavase de casuísmos, fugindo-se de tentativas abstratas. Edward S. Corwin enumera alguns exemplos desse vasto conjunto:

Incluem-se estes casos em várias categorias, algumas das quais tocam mais diretamente que outras o problemas da interpretação constitucional: 1) discussão da prova relativa à sanção de uma lei ou à ratificação de uma emenda constitucional; 2) impugnação de orientação dada às relações exteriores; 3) o término de guerras ou rebeliões; 4) a questão do que constitui uma "forma republicana de governo" e o direito de um Estado a receber proteção contra a invasão ou violência interna; 5) questões surgidas da ação política dos Estados ao determinar o modo de escolha dos Eleitores Presidenciais, funcionários estaduais e redistribuição das cadeiras do Congresso; 6) ações intentadas pelos Estados para pôr à prova seus direitos soberanos. (CORWIN, s/d, 172). 
Esse conjunto é isento do controle jurisdicional, tanto no âmbito externo, como também nos negócios internos governamentais. Dessa forma, norteado também pelo checks and balance, o poder judiciário não interferirá nos atos do Presidente nessa área.

\subsection{Papel de equilíbrio entre as jurisdições estaduais e federal}

Um entrave inicial a ser superado pelos estadunidenses, após a independência, residiu no fato de que, como herança da common law inglesa, desenvolveram um direito jurisprudencial, consequentemente a lei adotava um papel secundário. Ocorre que não seria exequível o estabelecimento das competências de cada ente, se não por meio do poder legiferante do Congresso Nacional, o qual deveria delimitá-las de maneira clara.

Invariavelmente, o principal elo que possibilitou a unidade de Estados tão díspares foi a própria Constituição Federal, superando-se um ponto controverso levantado por Tocqueville:

Uma primeira dificuldade deve ter se apresentado ao espírito dos americanos. Tratava-se de partilhar a soberania de tal sorte que os diferentes Estados que formavam a União continuassem a se governar eles mesmos em tudo o que dizia respeito apenas à sua prosperidade interna, sem que a nação inteira, representada pela União, deixasse de constituir um corpo e de prover a todas as suas necessidades gerais. Questão complexa e de difícil solução. (TOCQUEVILLE, 2005, p. 129-130).

A décima emenda à Constituição dos EUA estatuiu que a competência legislativa dos Estados seria a regra, comportando-se como de exceção a advinda das autoridades federais, desde que se fundasse na própria Constituição. Pautado nessa característica, os Estados desenvolveram corpos institucionais e jurídicos muito próprios de cada anseio local, até porque, antes da Guerra de Independência, as então 13 (treze) colônias, como elo comum, somente dispunham da submissão à metrópole inglesa, tornando-as extremamente heterogêneas.

O Congresso Nacional, receoso da dessemelhança entre os Estados, o que desencadearia não efetividade às normas emanadas, optou por se abster de legislar em muitas matérias que eram da sua competência, direcionando-as para a competência residual dos legislativos estaduais. Não obstante, havia um sério elemento complicador: a divisão da competência entre os Estados não se estabelece nos mesmos fundamentos que determinam a competência legislativa do Congresso Nacional, nem da dos Estados. 
Em 1789, almejando-se harmonizar o embate, o Congresso promulgou o Judiciary Act. Segundo essa legislação, em termos estritos, exceto quando não existisse lei federal, dever-se-ia aplicar o direito de um Estado. Caso não houvesse lei em um Estado, essa omissão não seria suprimida pela jurisprudência dele, consequentemente muitos questionaram essa liberdade da jurisdição federal. Contudo, permanecia a restrição de que a matéria fosse de competência federal, somente nesse caso poderia desenvolver as regras de uma common law federal.

Ao longo dos anos, a jurisprudência americana oscilou sobre a matéria. Um importante precedente originou-se da doutrina promovida pelo juiz Story no Caso Swift $v$. Tyson, datado de 1842, cuja tese fora aceita pela Suprema Corte. Nesse acórdão, ficou estabelecido que a jurisdição federal poderia estatuir alinhada com a general common law, desconsiderando a common law de um dado Estado.

Como consequência prática e amplamente criticada, um litígio passaria a ser solucionado de dois modos distintos, a depender da inclinação para a jurisdição do Estado ou da Federal. Consequentemente, a segurança jurídica dessas demandas tornava-se fragilizada. Ora, segundo os mais críticos, havia uma nítida ofensa à Constituição, pois reconhecia-se a supremacia das autoridades federais em temáticas, cuja incumbência inicial era destinada aos Estados.

O entendimento jurisprudencial anterior perdurou por quase um século, quando novamente questionou-se o cabimento de uma common law federal, isso na sentença proferida no Caso Erie Railroad Corporation v. Tompkins, em 1938. Em primeira e segunda instâncias, decidiu-se por manter o entendimento de que na ausência de lei escrita, aos tribunais federais era permitido que aplicassem a general common law. Ocorre que a Suprema Corte anulou a decisão proferida, estabelecendo a premissa do there is no federal general common law: salvo nas matérias devidamente regidas pela Constituição ou pelas leis do Congresso Nacional, a competência seria dos Estados, independente se procedida de uma lei escrita ou jurisprudência.

A fórmula de que não há common law federal não pode ser concebida de modo absoluto, pois há abrandamentos em algumas matérias, como por exemplo: marcas, patentes e direito marítimo.

A competência residual dos Estados não é ampla e irrestrita, mas se limita ao respeito dos princípios da Constituição, além de não promover empecilhos ao comércio interestadual. 
Particularmente quanto a essa segunda limitação, a Suprema Corte continuará pautada pela doutrina da "Moderação Judiciária", buscando o equilíbrio. Nesse tema, os inúmeros casos podem ser divididos em dois grupos: os pertinentes a tributos estaduais, indevidamente onerosos sobre o comércio interestadual; e os referentes a medidas regulamentadoras que impedem a livre circulação de comércio ente os estados.

A título esclarecedor dessa problemática comercial, cita-se o caso paradigmático Southern Pacific Co v. Arizona, de 1945. O Estado do Arizona promulgou uma lei de limitação ferroviária, na qual proibia a qualquer pessoa ou empresa, dentro dos seus limites territoriais, usar de trens com mais de 14 (catorze) carros de passageiros ou mais de 70 (setenta) vagões de carga. A Corte a declarou como inconstitucional, ante a imposição de obstruções ao comércio interestadual livre, além de ferir à política nacional proclamada pelo Congresso de promoção do serviço de transporte ferroviário adequado, econômico e eficiente. O mesmo raciocínio foi aplicado no Caso Morgan v. Viriginia, de 1946.

A unidade entre Estados tão divergentes, preservando o "estado de espírito dos juristas" estadunidenses, somente é possível pela Suprema Corte respeitar a soberania de cada Estado, simultaneamente em que mantem a autoridade estadual dentro dos limites do sistema federativo, tecendo uma organicidade ao conjunto. (DAVID, 2002, p. 470-472).

\subsection{Guardiã das liberdades civis}

Apesar de abdicar do protagonismo desempenhado antes de 1937, a Suprema Corte, após esse período, diferentemente de suas predecessoras (focadas na garantia do direito de propriedade), foi a mais atuante na definição de suas competências. Ela desenvolveu um papel de supervisora sobre os atos legislativos dos Estados e dos funcionários dos executivos estaduais, norteada por garantir as liberdades civis dos cidadãos.

As raízes desse posicionamento mais garantista procedem do cenário pós-Guerra Civil Americana, ocorrida entre 1861 e 1865. Essa guerra teve como resultados primordiais: a abolição da escravidão e preservação da unidade nacional, ante o desejo dos Estados Confederados da América em declarem sua secessão. Não obstante, como preço pago por essa "vitória", mais de 600 (seiscentos) mil americanos foram mortos.

Em vista do quadro devastador após o conflito armado, o Congresso Nacional promulgou as Emendas XIV e XV, datadas, respectivamente, de 1868 e 1870. Os legisladores 
nacionais perceberam que a proteção contra arbítrios do Governo Federal, estampada no Bill of Rights, não era suficiente para a pacificidade da União. Tais emendas passaram a garantir proteção judicial federal para o cidadão contra o seu Governo Estadual, de onde advinha o maior potencial de cerceamento às suas liberdades civis.

Pautada nessas novas emendas, a Suprema Corte trouxe para si a responsabilidade de evitar os cerceamentos de direitos civis promovidos pelos Estados, para tanto abandonou a presunção, existente anteriormente, da constitucionalidade das ações governamentais, não em sentido geral, mas especificadamente aos casos de liberdade pessoal. Essa "inversão do ônus probatório" tornou-se evidente em todos futuros julgados:

Na última década, porém, a Corte anunciou uma nova doutrina que, quando uma lei
parece usurpar um direito civil-em particular, a liberdade de palavra, de imprensa, de
religião e de reunião- deve admitir-se que a lei é nula, a não ser que os seus
defensores possam mostrar que a interferência é justificada em virtude da existência
de um 'perigo evidente e atual' para a segurança pública. (The Report of the
President's Committee on Civil Rights, 1947, p. 113 apud SCHWARTZ, 1955, p.
268-269).

Diante de inúmeros desrespeitos às liberdades civis pelos Estados, a Corte necessitou promover uma sistematização na análise. Para tanto, ela apoiou-se na teoria do "perigo evidente e atual" para apuração da violação ou não das liberdades civis, desenvolvida pelo juiz Oliver Holmes. A própria Corte explicou essa teoria no Caso Thomas v. Collins, de 1945:

Qualquer tentativa para restringir estas liberdades deve ser justificada pelo interesse público claro, ameaçado não de maneira duvidosa ou remota, mas pelo perigo evidente e atual. A ligação racional entre o remédio fornecido e o mal a ser evitado, que em outras circunstâncias pode suportar legislação contra o ataque sob o fundamento do processo legal regular, não será o bastante. Esses direitos repousam em bases mais firmes. Consequentemente, qualquer acontecimento que restrinja a discussão ordeira e a persuasão, no momento e lugar apropriados, deve apoiar-se claramente no perigo público, real ou iminente. Somente os abusos mais graves, que ponham em perigo interesses supremos, dão motivo à limitação admissível. (GRIFO NOSSO). (SCHWARTZ, 1955, p. 269).

Uma intensa discussão travada na Suprema Corte residiu na interpretação da primeira parte da Emenda I. Segundo essa: “O Congresso não legislará no sentido de estabelecer uma religião, ou proibindo o livre exercício dos cultos" $"$. Contudo, até 1948, não havia contornos nítidos se esse mandamento constitucional indicava uma separação absoluta entre Igreja e

\footnotetext{
${ }^{5}$ No original: "Congress shall make no law respecting an establishment of religion, or prohibiting the free exercise thereof." (UNITED STATES SENATE, 2018).
}

Revista Brasileira de Teoria Constitucional | e-ISSN: 2526-0251 | Porto Alegre | v. 4 | n. 2 | p. 44 - 65 | Jul/Dez. 2018 
Estado, ou se esse último poderia auxiliar na promoção da educação religiosa, desde que não houvesse discriminação de alguma religião em específico.

A matéria de liberdade religiosa é extremamente complexa, sendo difícil a enumeração de precedentes paradigmáticos, visto que em muitos casos, a Corte preocupa-se mais com as particularidades do caso em concreto.

Em 1948, no Caso Mccollum v. Board of Education, a Corte considerou inconstitucional uma lei do Estado de Illinois, segundo a qual o ensino religioso seria obrigatoriamente promovido nas escolas públicas por representantes das diferentes religiões como parte da grade curricular. Essa decisão de inconstitucionalidade baseou-se na premissa de que as escolas estaduais, mantidas pelos impostos dos cidadãos, não poderiam ser usadas como plataformas de propagação dos preceitos das diferentes religiões, o que infringiria a Emenda I.

Decorridos 4 (quatro) anos, em 1952, no Caso Zorach v. Clauson, a Corte não reproduziu a rígida separação entre Igreja e Estado vista anteriormente. Segundo uma lei do Estado de Nova Iorque, as escolas detinham a faculdade de liberarem seus alunos, durante momentos específicos das grades curriculares, para que se deslocassem aos locais religiosos que desejassem ou praticassem cultos religiosos tidos como legais ${ }^{6}$. A constitucionalidade foi declarada por não se utilizar do espaço público para promoção de religiões, consequentemente não havia gastos de verbas públicas.

Além das discussões envolvendo a religião, destacam-se a condição do negro e a liberdade de expressão e de imprensa. Quanto a liberdade de expressão, no Caso Joseph Burstyn, Inc. v. Wilson, de 1952, a Corte decidiu que os filmes também gozavam da imunidade de livre expressão, amparada na Emenda I.

\section{Evolução interpretativa da Suprema Corte ante a discriminação racial}

Apesar de compreendida a evolução interpretativa da Suprema Corte por meio dos precedentes atinentes às temáticas de religião, liberdade de expressão e de imprensa, invariavelmente, por meio da discussão da discriminação racial nos EUA que os impactos

\footnotetext{
${ }^{6}$ Houve grande polêmica se os preceitos dos Testemunhas de Jeová (Jehovah's Witnesses) eram legais, tanto que em mais de uma dezena de leis foi proibida em diversos Estados. A Suprema Corte invalidou todas essas.
} 
desse fenômeno são melhores sentidos, não somente na ordem jurídica, mas principalmente na sociocultural.

Frequentemente, atribui-se como um dos grandes legados da Guerra Civil a extinção da escravidão, consequentemente da igualdade jurídica entre os negros e os brancos. Sem embargo, desconsidera-se que essa grande "vitória" estava atrelada ao plano formal, dissociada do material, em que, já no período pós-guerra, diversos mecanismos excludentes foram criados pelos "antigos senhores", visto esses considerarem inadmissível compartilhar da mesma "liberdade" com seres, que até pouquíssimo tempo antes, eram tidos como suas mercadorias. Em semelhante análise, Alexis de Tocqueville concluiu, ainda em 1825:

Se se torna livre, a independência muitas vezes lhe parece um grilhão ainda mais pesado que a própria escravatura; pois, no curso de sua existência, aprendeu a submeter-se a tudo, exceto à razão; e, se a razão se tornasse seu único guia, não lhe saberia reconhecer a voz. Mil novas necessidades o assediam, e faltam-lhe os conhecimentos e a energia necessários para resistir a elas. As necessidades são amos que cumpre combater, mas ele aprendeu apenas a se submeter e a obedecer. Chegou, então, a este cúmulo de miséria, em que o cativeiro o embrutece e a liberdade o faz perecer. (TOCQUEVILLE, 2005, 375).

Essa herança cultural terá reflexos até os dias atuais, em que estados sulistas, pelo passado escravagista, consideram os negros como cidadãos de "segunda classe". Recorre-se ao Caso Scott v. Sandford (1856), julgado paradigmático em que o então presidente da Suprema Corte, Roger Taney, escreveu a opinião de que como Scott era negro, ele não era cidadão e, portanto, não tinha o direito de processar o Estado. Nas palavras da Corte:

4. Um negro livre da raça africana, cujos ancestrais foram trazidos para este país e vendidos como escravos, não é um "cidadão" dentro do significado da Constituição dos Estados Unidos. 5. Quando a Constituição foi adotada, eles não eram considerados em nenhum dos Estados como membros da comunidade que constituía o Estado, e não estavam contados entre seus "cidadãos ou pessoas". Consequentemente, os direitos e imunidades especiais garantidos aos cidadãos não se aplicam a eles. E não sendo "cidadãos" dentro do significado da Constituição, eles não têm o direito de processar esse personagem em um tribunal dos Estados Unidos, e o Tribunal de Circuito não tem jurisdição em tal processo. (TRADUÇÃO NOSSA). ${ }^{7}$

\footnotetext{
${ }^{7}$ No original: "4. A free negro of the African race, whose ancestors were brought to this country and sold as slaves, is not a "citizen" within the meaning of the Constitution of the United States. 5. When the Constitution was adopted, they were not regarded in any of the States as members of the community which constituted the State, and were not numbered among its "people or citizens." Consequently, the special rights and immunities guarantied to citizens do not apply to them. And not being "citizens" within the meaning of the Constitution, they are not entitled to sue in that character in a court of the United States, and the Circuit Court has not jurisdiction in such a suit." (SUPREME COURT OF THE UNITED STATES, 2018). Para maiores aprofundamentos, recomenda-se (RODRIGUES, 1992, p. 92-96).
}

Revista Brasileira de Teoria Constitucional | e-ISSN: 2526-0251 | Porto Alegre | v. 4 | n. 2 | p. 44 - 65 | Jul/Dez. 2018 
Leviana uma análise que tentasse sobrepor-se aos elementos históricos da formação da discriminação racial, conquanto ações dos legislativos e do judiciário também tiveram uma grande contribuição. Se em um primeiro momento, ambos legitimavam a "lógica de dominação" dos brancos e possibilitavam a tolerância da ordem jurídica, paulatinamente, especialmente o judiciário, por meio da Suprema Corte, tentou romper com essa profunda contradição ao tão valorizado sentimento de liberdade americano:

Nós nos orgulhamos da liberdade desfrutada por nosso povo, em comparação com todos os outros povos. Mas é difícil conciliar esse orgulho com um estado de lei que, praticamente, põe a marca da servidão e degradação numa grande classe de nossos concidadãos, nossos iguais perante a lei. (163 U.S em 562 apud SCHWARTZ, 1955, p. 275).

A Suprema Corte, mesmo no auge da doutrina da "Supremacia Judiciária", apesar de vangloriar-se da independência da pressão política, invariavelmente, como qualquer tribunal, encontra-se atrelada a influência do sentimento popular. Tanto o é que, ao se fazer uma análise cronológica dos seus precedentes, depara-se que a Corte buscou promover mudanças graduais no desmantelamento do preconceito racial, visto que ponderava seriamente que "guinadas bruscas" jurisprudenciais não teriam efetividade caso a sociedade não tivesse atingido uma maturidade para tanto.

Os parâmetros seguidos pela Corte para se auferir a constitucionalidade de práticas discriminatórias alicerça-se nas emendas XIII, XIV e XV. Essa postura novamente ratifica o papel dela em ser guardiã das liberdades civis, ao salvaguardar os direitos dos grupos minoritários, diferindo-se das suas predecessoras.

Em concordância com o acentuado, essas emendas advieram no período pós-Guerra Civil com o intuito de possibilitar ao negro emancipado uma condição de plenitude e igualdade na sociedade estadunidense. Inicialmente, a emenda XIII proibiu a escravidão e a servidão involuntária, exceto essa última da modalidade de castigo por crime. Contudo, diante da contumácia de "antigos senhores" em manter suas "mercadorias" escravizadas, elaborou-se a emenda XIV, focada em garantir mais segurança a liberdade dos ex-escravos. Na tentativa de se romper com uma lógica formalista, buscando-se a efetividade dos direitos dos negros, culminou a emenda XV, ao garantir o direito de voto a todos os cidadãos sem discriminação. Sob uma perspectiva crítica, obviamente que essas emendas não teriam a capacidade per si de alterarem esse quadro cultural. 
Apesar da amplitude do tema, imergir-se-á em três das mais importantes manifestações de discriminação contra o negro: restrições ao direito de voto, contratos restritivos por motivos raciais e segregação socioespacial.

\title{
2.1. Restrições ao direito de voto
}

A emenda XV, datada de 1870, definiu, em sua seção 1, que o "direito de voto dos cidadãos dos Estados Unidos não poderá ser negado ou cerceado pelos Estados Unidos, nem por qualquer Estado, por motivo de raça, cor ou de prévio estado de servidão."8 Apesar da formalização teórica da proibição de interferência no direito de voto por motivos raciais, a emenda não adentrou nos mecanismos para se conceder efetividade a isso.

Os estados sulistas consideravam essa emenda como uma coação imposta pelos estados nortistas, vitoriosos na Guerra Civil. Consequentemente, desenvolveram mecanismos para a burlarem, almejando que sem sufrágio, os negros não poderiam votar e não exercer pressão política para alteração do status quo existente. Como ilustração desse quadro, Tocqueville, novamente, acentuou:

\begin{abstract}
Em quase todos os Estados em que a escravidão foi abolida, deram-se ao negro direitos eleitorais; mas se ele se apresenta para votar corre risco de vida. Oprimido, pode se queixar, mas só encontra brancos entre seus juizes. A lei, no entanto, abrelhe o banco dos jurados, mas o preconceito afasta-o dele. [...] Permite-se que o negro implore ao mesmo Deus dos brancos, mas não no mesmo altar. Ele tem seus padres e seus templos. Não lhe fecham as portas do céu, porém a desigualdade mal se detém à beira do outro mundo. Quando o negro falece, jogam seus ossos em separado, e a diferença de condição se encontra até mesmo na igualdade da morte. (TOCQUEVILLE, 2005, p. 397).
\end{abstract}

Nessa esteira de mecanismos ardilosos, destaca-se o Caso Guinn v. United States, de 1915, em que a Suprema Corte discutiu a validade da "cláusula avoenga", presente na Constituição do Estado de Oklahoma: nenhum cidadão, ou descendente seu, poderia votar caso não se submetesse a determinados exames educacionais em $1^{\circ}$ de janeiro de 1866 . A Corte declarou a inconstitucionalidade dessa cláusula, pois baseava-se em um período anterior à promulgação da Emenda XV (1870), impossibilitando que os negros votassem.

Historicamente, os estados do Sul têm uma afinidade ideológica com o Partido Democrata. Aproveitando-se dessa constatação, o legislativo do Texas promoveu uma lei que

\footnotetext{
${ }^{8}$ No original: "The right of citizens of the United States to vote shall not be denied or abridged by the United States or by any State on account of race, color, or previous condition of servitude." (UNITED STATES SENATE, 2018).
} 
privava os negros sulistas de votarem nas primárias ${ }^{9}$, restringindo o acesso ao Partido Democrata aos brancos. As primárias constituem uma prática essencial do sistema eleitoral estadunidense; representam uma eleição indireta, em que eleitores votam em "delegados compromissados" (pledged), ou seja, pessoas que se comprometem moralmente a votar em determinado pré-candidato. Esses delegados que votarão diretamente nos candidatos que ocuparão os cargos.

A Corte, ao analisar o Caso Nixon v. Herndon, de 1927, considerou essa legislação como inconstitucional, visto que os negros eram segregados totalmente de externar seus votos nesse estado.

Inconformado com a declaração de inconstitucionalidade proferida, o Legislativo texano promulgou uma nova lei em que legitimava que a comissão executiva estadual de um partido político poderia estabelecer qualificações para os seus membros votarem. Mediante cabimento legal, a comissão executiva estadual dos democratas adotou uma resolução de que somente brancos poderiam votar nas primárias desse partido. Novamente, a Corte declarou a inconstitucionalidade dessa legislação no Caso Nixon v. Condon, de 1932, pois a incumbência de uma comissão executiva advinha do governo, consequentemente, enquadrada na proibição da emenda XV.

Ocorre que houve uma fragilização na ratio decidendi promovida pela Suprema Corte nos casos anteriores, que viria a ser aproveitada pelo Partido Democrata do Texas. A Corte considerou as legislações anteriores como inconstitucionais, já que seus atos discriminatórios equivaliam à ação do Estado dentro da proibição constitucional. Pautado nisso, ainda em 1932, os democratas texanos aprovaram uma resolução de que somente os brancos poderiam votar nas primárias do partido. Ao ser apreciado pela Suprema Corte em 1935, no Caso Grovey v. Townsend, a mesma decidiu pela constitucionalidade, em decorrência dessa resolução não ser uma "ação do Estado", conforme depreendido das emendas XIV e XV, mas apenas uma decisão de uma organização particular.

Nesse ponto histórico, faz-se necessário pontuar que mesmo o sufrágio dos negros datar de 1870, com a emenda XV, até a presente data, decorrido mais de meio século, não o gozaram de maneira plena. Essa situação ainda se perduraria até 1944, quando a Suprema

\footnotetext{
${ }^{9}$ Para maiores aprofundamentos, recomenda-se (HAMILTON et al, 2002, p. 361-369, 409-412); e (COOLEY, 2002, p. 245-263).
}

Revista Brasileira de Teoria Constitucional | e-ISSN: 2526-0251 | Porto Alegre | v. 4 | n. 2 | p. 44 - 65 | Jul/Dez. 2018 
Corte reconheceu, ao apreciar o Caso Smith v. Allwright, que embora a filiação a um partido político não fosse um "ato do Estado", quando esse exigia uma qualificação necessária para votar numa primária, o próprio Estado tornava essa ação particular em uma sua.

Apesar da criação de um arcabouço jurídico para proteção dos direitos de voto dos negros pela Suprema Corte, em diversos Estados do Sul, houve frequentes ameaças e intimidações àqueles para que os resultados eleitorais fossem manipulados. Apesar dessa evidência, não se despreza a grande contribuição da Corte para se tentar superar a igualdade meramente formal.

\subsection{Contratos restritos por motivos raciais}

Em decorrência da pujança que ostentava como maior metrópole do globo, os juristas estadunidenses, por um longo período, consideravam a Inglaterra como modelo a ser seguido. Acentua-se que esse sentimento perdurou, mesmo após a independência, visto que ainda havia uma diferença gritante entre a ex-colônia e a ex-metrópole, evidente nos avanços econômicos e culturais.

Como reflexo disso, os tribunais estadunidenses incorporaram a doutrina desenvolvida por Charles Pepys, Lorde Cottenham, no Caso Tulk v. Moxhay, de 1848: dentro dos limites de competência, os tribunais respeitariam restrições aos bens imóveis contidas em um contrato de compra e venda, tanto em relação ao compromitente original, como os proprietários subsequentes, os quais deveriam ser notificados da restrição. Ocorre que esse instituto jurídico foi empregado na América como meio de restrição da propriedade imobiliária pelo negro.

Os Estados sulistas apropriaram-se dessa doutrina e a potencializaram em políticas de organização do território. No Caso Buchanan v. Warley, de 1917, questionou-se uma lei municipal em que determinava restrições de acesso de uma etnia aos quarteirões em que a quantidade de residências majoritárias fosse de outra. Em termos claros, negros não poderiam residir em quarteirões em que fossem predominantes ocupados por brancos e vice-versa. A Suprema Corte declarou a inconstitucionalidade, pois restrições promovidas pelas autoridades estaduais equivaliam à segregação de etnias, violando-se a cláusula de igual proteção da emenda XIV.

A fundamentação do precedente Buchanan v. Warley residia na impossibilidade de restrições promovidas pelo Estado, não englobando proteção contra condutas particulares, por 
mais discriminatórias que fossem. A Suprema Corte confirmou essa linha argumentativa no Caso Corrigan v. Buckley, de 1926, ao afirmar que a proibição é exclusivamente aos Estados e não aos particulares, conforme estampado na seção 1 da emenda XIV:

Todas as pessoas nascidas ou naturalizadas nos Estados Unidos e sujeitas a sua jurisdição são cidadãos dos Estados Unidos e do Estado onde tiverem residência, Nenhum Estado poderá fazer ou executar leis restringindo os privilégios ou as imunidades dos cidadãos dos Estados Unidos; nem poderá privar qualquer pessoa de sua vida, liberdade, ou bens sem processo legal, ou negar a qualquer pessoa sob sua jurisdição a igual proteção das leis." (TRADUÇÃO NOSSA). ${ }^{10}$

A Suprema Corte desconsiderou que os contratos, independentemente de restritivos ou não, são executados por intermédio do próprio Estado, garantindo segurança jurídica e executoriedade. Essa lacuna foi suprida em 1948, no Caso Shelley v. Kraemer, em que a Corte sustentou, alicerçada na emenda XIV, a proibição da executoriedade de contratos restritivos, pelos tribunais estaduais, nos quais houvesse a finalidade de exclusão de propriedades imobiliárias por motivos raciais. Portanto, superou-se a doutrina Corrigan v. Buckley, englobando também os atos discriminatórios promovidos por privados.

No Caso Shelley v. Kraemer, o então presidente da Suprema Corte, Frederick Moore Vinson, não adentrou na validade dos contratos restritivos, tanto que não os considerou como ineficazes. Ele afirmou que se as finalidades dos contratos restritivos fossem efetuadas por obediência voluntária, não existiria "atos de Estado" e a emenda XIV não seria violada. O determinado, nesse momento, foi que os contratos restritivos não gozariam de proteção ao se submeterem ao crivo do judiciário.

Novamente, apesar de algumas limitações no plano teórico, a Suprema Corte desempenhou um papel imprescindível na busca da concretização dos direitos formalizados nas emendas.

\subsection{Segregação socioespacial}

A segregação racial, promovida especialmente pelos sulistas, aos negros pautou-se nas Leis Jim Crow, perpetuando de 1876 a 1965, ou seja, durante aproximadamente um

\footnotetext{
${ }^{10}$ No original: "All persons born or naturalized in the United States and subject to the jurisdiction thereof, are citizens of the United States and of the State wherein they reside. No State shall make or enforce any law which shall abridge the privileges or immunities of citizens of the United States; nor shall any State deprive any person of life, liberty, or property, without due process of law; nor deny to any person within its jurisdiction the equal protection of the laws." (UNITED STATES SENATE, 2018).
}

Revista Brasileira de Teoria Constitucional | e-ISSN: 2526-0251 | Porto Alegre | v. 4 | n. 2 | p. 44 - 65 | Jul/Dez. 2018 
século. Consoante essas leis, qualquer empresa de transporte que conduzisse passageiros brancos e negros no mesmo veículo, cometeria uma ilegalidade, submetida a sanções.

Em 1896, o Caso Plessy v. Ferguson desencadeou uma ampla repercussão nos Estados do Sul. Questionava-se uma lei de Luisiana em que havia acomodações ferroviárias separadas para os passageiros negros e brancos. A Corte ao apreciar o caso, julgou que não haveria discriminação aos negros, desde que as acomodações concedidas a esses substancialmente fossem iguais aos dos brancos. Essa mentalidade não se restringiu a acomodações em transportes, incluindo oportunidades educacionais, especialmente, um ensino superior de mesma qualidade, mesmo que segregados negros de brancos.

Pautado no precedente Plessy v. Ferguson, o Estado do Texas direcionou seus esforços em garantias formais aos negros, contudo, geralmente, em termos práticos, havia uma desigualdade na formação educacional e, consequentemente, das oportunidades profissionais. O governo texano inaugurou uma faculdade de Direito exclusiva para os negros, objetivando impedir o acesso desses a faculdade dos brancos. O peticionário, em 1950, no Caso Sweatt v. Painter, questionou a impossibilidade de estudar na faculdade do Texas destinada aos brancos, visto a superioridade da mesma. O presidente da Suprema Corte, Frederick Moore Vinson, reconheceu a discrepância existente e a infração a emenda XIV, que preconiza a cláusula de igual proteção.

Precipitada uma análise ampliativa do Caso Sweatt v. Painter, já que se limitava ao plano do ensino superior. A Corte, portanto, desconsiderou que a segregação continuava a existir em várias ocasiões e extratos sociais, nos quais os negros ainda se viam em uma condição de inferioridade, e o pior, legitimada pelo Estado.

Como um dos principais marcos da luta pela superação da segregação, salienta-se o Caso Brown v. Board of Education, de 1954. Crianças negras defendiam o seu direito, pautadas na emenda XIV, de serem admitidas em escolas primárias e secundárias destinadas aos brancos, invalidando-se o critério de segregação. Interessante que elas perderam em $1^{\circ}$ grau, dado que os Tribunais Inferiores, pautados no Caso Plessy v. Ferguson, advogaram que as escolas dessas eram iguais em todos os sentidos possíveis das dos brancos, desde a qualidade dos professores até a estrutura física. Inconformados, os autores recorreram a Suprema Corte almejando a superação do mencionado precedente.

O caso citado gerou um amplo impacto no cenário nacional, tanto que a Corte somente o decidiu definitivamente depois de 2 (dois) anos. Pautado no voto unânime da 
Corte, o presidente Earl Warren proclamou que a segregação das crianças violava a garantia constitucional de iguldade, impondo-as um sentimento de inferioridade quanto ao seu papel na comunidade, além do que era inconcebível a mentalidade de "separados, porém iguais". A separação, de forma inerente, desencadeava desigualdade.

Sob um viés crítico, houve ainda profundas discordâncias à Corte por não ter aplicado a mentalidade Brown v. Board of Education de forma irrestrita e ampla. A efetividade dessa "vitória" foi questionada pelo impacto provocado no estado anímico dos brancos sulistas, por ainda cultivarem o preconceito racial. ${ }^{11}$ Todavia, não se despreza a tolerâncias proporcionada pelos meios legais, onde o Estado garante o respeito aos negros no plano material, mesmo que os opositores o façam forçosamente ou externem um comportamento de antipatia.

\section{Considerações finais}

Diante dos diversos precedentes apreciados pela Suprema Corte, infere-se a maleabilidade que ela proporciona à Constituição dos EUA, no qual seu caráter sintético e rígido em suas alterações não foram empecilhos para que a lei fundamental acompanhasse os avanços socioculturais. A estabilidade das instituições jurídicas e políticas foi não só devidamente preservada, como amadureceu aos clamores das minorias que poderiam vir a ser subjugadas pela democracia.

O sistema judiciário, se em um primeiro momento legitimou distorções nas garantias fundamentais a certos cidadãos por outros semelhantes ou por entes estatais, corrigiu de maneira lenta mazelas encrustadas no seio da sociedade norte-americana. Essa aparente lentidão, sob hipótese alguma refletiu inércia, mas buscou que a sociedade acompanhasse tais mudanças e, consequentemente, o estatuído nas leis superasse meras folhas de papéis e fossem "vivas".

Orientada por uma postura mais branda, de não enfrentamento ao legislativo, a Corte concedeu solidez à proteção das liberdades civis, incluindo a liberdade religiosa, de expressão e de imprensa. Não retirando a relevância dos mencionados direitos, a maior parte dos esforços foram concentrados na tentativa de se extirpar do meio jurídico e social a

\footnotetext{
${ }^{11}$ Tcqueville, ainda no século, XIX anunciou: "Os modernos, depois de abolirem a escravidão, ainda precisam destruir três preconceitos muito mais inefáveis e tenazes que ela: o preconceito do senhor, o preconceito de raça e, enfim, o preconceito do branco." (TOCQUEVILLE, 2005, p. 396).
} 
mentalidade da inferioridade dos negros, a qual remonta à Guerra Civil. Como um presságio, Tocqueville, ainda no século XIX, anunciou:

\begin{abstract}
Se a América passar um dia por grandes revoluções, elas serão provocadas pela presença dos negros no território dos Estados Unidos: isto é, não será a igualdade de condições, mas sua desigualdade que as fará nascer. Quando as condições são iguais, cada um se isola em si mesmo e esquece o público. Se os legisladores dos povos democráticos não procurassem corrigir essa funesta tendência ou a favorecessem, com a idéia de que ela desvia os cidadãos das paixões políticas e os afasta assim das revoluções, é possível que eles próprios acabem produzindo o mal que querem evitar e que chegaria um momento em que as paixões desordenadas de alguns homens, ajudados pelo egoísmo ininteligente e pela pusilanimidade da maioria, acabassem forçando o corpo social a passar por estranhas vicissitudes. (TOCQUEVILLE, 2002, p. 321).
\end{abstract}

Ao se impor como guardiã da Constituição Federal, a Suprema Corte supera uma eventual carência de legitimidade democrática concedida aos demais poderes. Da mesma forma, como parte integrante do judiciário, ela possibilita uma dinamicidade ao Executivo e Legislativo, cada qual com sua competência originária preservada em consonância com o "espírito de liberdade" dos Founding Fathers, sem embargo da preservação do núcleo essencial de proteção às garantias fundamentais.

\title{
Referências
}

UNITED STATES SENATE. Constitution of the United States, 2018. Disponível em: https://www.senate.gov/civics/constitution_item/constitution.htm. Acesso em 31 de maio de 2018.

COOLEY, Thomas M. Princípios gerais de Direito Constitucional nos Estados Unidos da América. Tradução de Ricardo Rodrigues Gama. Campinas: Russell, 2002.

CORWIN, Edward S. A Constituição norte-americana e o seu significado atual. Rio de Janeiro: Zahar, s/d.

DAVID, René. Os grandes sistemas do direito contemporâneo. Tradução de Hermínio A. Carvalho. 4 ed. São Paulo: Martins Fontes, 2002.

HAMILTON, Alexander; MADISON, James; e JAY, John. O federalista. Tradução de Hiltomar Martins Oliveira. Belo Horizonte: Ed. Líder, 2003.

KETCHAM, Ralph. Escritos anti-federalistas y debates de la convención constitucional de E.E. U.U. Tradução de Jorge Rizzo e Mónica Rebollo. Barcelona: Hacer Editorial, 1996. 
RODRIGUES, Lêda Boechat. A Corte Suprema e o Direito Constitucional Americano. 2 ed. Rio de Janeiro: Civilização Brasileira, 1992.

SCHWARTZ, Bernard. Direito constitucional americano. Tradução de Carlos Nayfeld. Rio de Janeiro: Forense, 1955.

SUPREME COURT OF THE UNITED STATES. Scott v. Sandford, 60 U.S. 393 (1856), 2018. Disponível em: https://supreme.justia.com/cases/federal/us/60/393/. Acesso em 17 de julho de 2018.

TOCQUEVILLE, Alexis. A democracia na América: leis e costumes de certas leis e certos costumes políticos que foram naturalmente sugeridos aos americanos por seu estado social democrático. Tradução de Eduardo Brandão. 2 ed. São Paulo: Martins Fontes, 2005.

. A democracia na América: sentimentos e opiniões: de uma profusão de sentimentos e opiniões que o estado social democrático fez nascer entre os americanos. Tradução de Eduardo Brandão. 1 ed. 2 tir. São Paulo: Martins Fontes, 2000. 